\title{
An Investigation of Co-Habitation and Academic Achievement among Students of Tertiary Institutions in Niger State, Nigeria
}

\author{
${ }^{1}$ Dr. Aremu, O. D. ${ }^{2}$ Dr. (Mrs) Aliyu, M. A. ${ }^{3}$ Dr. Jibril, A. T \& ${ }^{4}$ Aminu Abubakar \\ ${ }^{1,2,3 \& 4}$ School of General Education, Federal College of Education \\ Kontagora,Niger State, Nigeria
}

\begin{abstract}
The study focused on investigating co-habitation and academic achievement among students of tertiary institutions in Niger State, Nigeria. Two research questions and hypotheses were formulated to guide the study. The research design adopted for the study was the descriptive survey design with a population of 7,701 final year students of tertiary institutions. Stratified and simple random sampling techniques were used to select the required respondents for the study. A sample of 710 final year students' of three tertiary institutions namely one Federal University, one Polytechnic and one College of Education were used in the study. The instrument for data collection was a researchers' developed instrument entitled "Investigation of Co-habitation and Academic Achievement Score (PCAAAS)". To ascertain the face and content validity of the instrument, it was given to three experts two in Measurement and Evaluation and one in Guidance and Counselling for appropriate modifications. The reliability of the instruments was established using the split-half reliability coefficient method. and the index ranged from .71 to .82 which was found reliable enough for data collection. The analysis was executed with descriptive and inferential statistical analysis such as mean, standard deviation, population t-test, and One-way ANOVA and the findings revealed that the level of cohabitation among students is a high level of cohabitation. Also, social factors have an influence on the academic performance of cohabiting students as the majority of the students indicated that most of them cohabit to gain social influence and protection from their spouse. It was recommended among others that parents should have interest and concern in terms of unprecedented visits to their children staying on campus to see how they are faring in school.
\end{abstract}

Keywords: Investigation, Co-habitation, Academic Achievement, Tertiary Institutions, Niger State, Nigeria.

\section{INTRODUCTION}

Education is a vital societal that is not only geared towards assisting the learner to inculcates the essential skills, abilities and knowledge among the individuals, but also leads to overall growth and progress of the individuals, community and nation as a whole. An educated person is not only anaccomplish scholar, but is also regarded as one who renders an efficient contribution towards the well-being of the community. The inculcation of academic knowledge, skills, abilities and proficiency among the individuals is enhanced through learning and academic performance. The expectation of any academic system is quality performance/ achievement among learners (Nyagosia, 2011). This is because students are the primary target of every academic institutions as such it is expected that the environment such be such that foster learning outcome among students.

In most tertiary institutions there has been persistent outcry on the poor performance of students'on and off campus. Campus cohabitating is the factor this study tends to consider as it affectsstudents academic performance. Cohabitation refers to a situation in which two people live together and are involved in an emotional and or sexual intimate relationship. Cohabitation can also be defined as a living arrangement in which an unmarried couple living together in a long term relationship that resembles a marriage couple cohabitating rather than marry for a variety of reasons. Cohabitation is not commonly used to describe people who are sharing a living space or those called 'roommates', It is most commonly used in reference to heterosexual couples (Clarkberg, Ross, Stolzenberg\& Linda, 2015). Thus is on the basis that they stay and spend their lives together without any legal backing.

Campus cohabitation is the situation where two students, a male and a female live together as married couple but they are not married. There are common reasons for campus cohabitation such as, to find out if they are compatible for marriage to have efforts to spend more time together so as to weave their routine and interest access their relationship. Another strong reason is for them to save money. Their money will be joined, used together seeing it as a way to save on rents, good and other living expenses. 
Cohabitation has negative effect such as breaking up at last, the commitments on both partners may become too unbearable for one and so misunderstanding set in and the relationship fails. Cohabitating is a phenomenon pervading most, if not all the tertiary institutions in Nigeria today the act is so rampant to the extent that it has become the usual; way of the life on our campuses. Some social gatherings in schools give awards to best cohabitating couples and those involve see nothing wrong with it rather they are been proud and even the society.

According to Kramer (2004), the dangers associated with cohabitation are pronounced and their consequences bounce back on the academic achievement of those involve, some of these dangers arte (i) high rate of absorption in tertiary institution (ii) the threat of sexual transmitted diseases (iii) those involve indulge in other vices like stealing, lying, cheating etc. (iv) monotonous fondness. Cohabitation is highly absorbed in our society today that those who have involved preached its benefits to their mates that many embrace it. As the rate of tertiary institution students cohabiting has greatly increase. So the percentage of student academic achievement in schools has greatly dropped as a result of the "octopus" called cohabitation.

Most partners cohabiting have sexually transmitted diseases that can be easily transmitted to his/her partners. So as the rate of cohabitation increases report cases of sexually transmitted diseases also increases when a student is side, such will not be able to carrying out any academic activity, which is the beginning of failure. It may eventually lead to death which is the end of all academic achievement. Observation and personal interaction has also shown that those involve in cohabitation indulge in other anti-social ills such as, stealing, lying, clubbing, cheating, killing etc, a male partner cohabiting with is partner will like to impress the lady so that she does not leave her for another and this require money which he may not have and as such go on to commit lot of atrocities in other to meet with the challenging demands of the opposite sex (Ofoegbu, 2002). This implies that most students who cohabit do that for the sake of financial benefit which is attributed to hardship.

Clarkberg, Ross, Stolzenberg and Linda (2015) informed that most students rather than thinking of their academic work load in school rather deviate to think of dubious ways to get money in order to satisfy the girl/boyfriends. In those days cohabitation was highly unethical, obscure and even taboo among people. Non-marital unions have become common because the meaning of the family has been altered by individualistic social value have progressively matured since the late 1940s (Ogunsola, 2004). Sociologists treat cohabitation as a distinct occurrence not just because it has a negative effect on the school performance of the students, but because it is an unhealthy practice with economic, social, educational and religious implications to the family and society at large. In the past cohabitation before marriage was not viewed as the right thing to do, it is now sometimes seen as a "necessity." Some people do it out of preparation for marriage, while others do it out of convenience.

The increase in population of undergraduate students and the inability of the government to adequately provide the needed social infrastructures and funding of higher education in Nigeria has led to risky coping mechanisms among the students. Students of tertiary institutions have been involved to a deviant form of cohabitation known as "campus marriage" among students. A situation where students of opposite sex are forced to live together and share things in common without any authorization portends danger to the sanctification of the institution of marriage and family. It is against the norms and values of our society to allow young and unmarried couple to live together especially where they do not have any family affinity. Most students that live together do not allow their parents to know about it. This therefore exposes the students to all forms of risk and harm as they continue to cohabit. Students who live together with their partners lack both family susceptible to attack and abuse by both outsiders and even their partners. Often times the society frowns at unmarried adults cohabiting within the society. Most institutions make laws to control indecent dressing among students without paying attention to cohabitation among them.

Let students on campus and society at large jointly say No to cohabitation, because it shall be later discover and then spare yourself the pain and grief of knowing that you were being used rather than been loved and then, it may be that academic, it has been too late. It is against this backdrop that the study was carried out on investigation of Co-habitation and Academic Achievement among Students of Tertiary Institution in Niger state of Nigeria.

\subsection{Level of Cohabitation}

Cohabitation as a form of relationship is highly popular among young adults, particularly those in tertiary institutions who are not close to their parents. Their quest for independence and love for opposite sex has been attributed as the remote cause of cohabitation. Ermisch and Francesconi (2000) informed that most students cohabit due to poverty, inability to secure accommodation for themselves and other related factors like poor economic condition and poor educational background. Svodziwa and Kurete (2017) noted that cohabitation among students is mostly associated to or caused by inadequate accommodation.

Cohabitation is an intimate sexual union between two unmarried partners, who share the same living quarter for a sustained period of time. Cohabitation according to Bower and Christopher (2001) sees cohabitation as a union of persons of the opposite sex living together but not married. An increase in the acceptability of cohabitation can be viewed as evidence of the 
weakening social norms related to marriage, known as deinstitutionalization of marriage (Bumpass \&Lu, 2000). This implies that the level of cohabiting unions were common to some sub-groups such as the poor, those whose marriages had broken-up, some rural dwellers and those who were ideologically opposed to marriage (Kiernan, 2001). During the late 2000 and early 2001 , the institution of marriage began to change fundamentally in many parts of Nigeria, This leads to cases where couples began to live together outside of marriage (Perelli-Harris \&Gassen, 2012). In addition, some social changes has led to weakening traditional and religious authority, increasing individualism, urbanization, mass education, rising women's socioeconomic status and the growth of consumerism (Mashau, 2011). To this end, the level of awareness in the society can limit te spread of cohabitation among students.

In most part of Africa, cohabitation could be attributed to colonialism; it gradually broke down African communal living patterns, by the acculturation of foreign cultural norms and value. This transcended to an outgrowth of historical changes in sexual behaviour such as the increased acceptance of sexual relations outside of marriage that emanate from the rise of the ideology of individualism (Rindfuss\&VandenHeuvel, 2000). This ideology of individualism is exacerbated by rapid urbanization, housing problems and homelessness.

This has resulted in different union formations ranging from overcrowding to cohabitation in African urban centres. Omonijo (2015) attribute the prevalence (high level) of cohabitation among Nigeria youths to sex revolution in Europe and America. The author emphasised that the impact of foreign ideas, values and norms as well as social and mass communication and conditions of urban life on the behaviour and attitude of Nigerian adolescents are on the increase.

\subsection{Social factors influencing cohabitation and students academic achievement}

The increase in the number of people who live in the arrangement of non-marital cohabitation is a particularly visible change that has occurred in family life in the recent past. It is a subject that has been the focus of considerable attention in the media and in academic research, too. In these both these spheres cohabitation is often described as a modern alternative to marriage, an alternative that could be considered the logical outcome of the greater autonomy and freedom that individuals enjoy today in the modern society (Rabušic, 2001). In the early 1990s some Czech demographers began to predict that cohabitation would soon begin to spread throughout post-revolution, Czech society to a much greater degree (Vereš 2011).

There are two basic questions which relate to cohabitation and which are of particular interest from the social perspective. Though the two are tightly intertwined, it is of use, at least analytically, to distinguish between them. The first refers to the socio-demographic differences between those who enter into marriage and those who live in co-habitation, and/i.e. the differences between those who enter directly into marriage and those who opt for cohabitation prior to marriage. The question in this case is whether the decision in favour of marriage or cohabitation is the result of relatively arbitrary values and preferences, and whether and how the decision is dependent on more 'objective' realities, e.g. the actual socio-economic standing of the people involved, their social group, class, or position on the 'marriage market', and whether then it is a matter of a relatively rational reaction to the circumstances people are living in (Kiernan 2000).

The second question addresses the qualitative differences between marriage and cohabitation, i.e. what types of partnership do both types of union represent and what are their features. Many of the differences between marriage and cohabitation can be attributed to social differences, because people who live in a marriage arrangement simply differ from people who live in an arrangement of cohabitation. However, from the social perspective it is important to ask whether there also exist institutional differences that are intrinsic to the type of union. In essence this is a question of whether marriage or cohabitation leads by definition to different partnership arrangements, and whether and in what way the absence of a legal bond in the case of cohabitation has an effect on the partnership. This article focuses on the second of the two basic questions indicated above, and pays particular attention.

Zheng (2011) carried a study in Canada, non-marital cohabitation has become a normative life experience, but there are uncertainties regarding its contribution to social cohesion. This article compares and contrasts cohabitation with marriage (and other marital statuses) on two dimensions of social engagement: social networks and pro-social behaviour. The study employs GSS-17 micro data and logistic regression analysis. The findings illustrate that social factors is a strong determinant of cohabitation among students in tertiary institutions.

\section{STATEMENT OF THE PROBLEM}


Cohabitation is a phenomenon pervading most, if not all, of the tertiary institutions in Nigeria today. The practice is so rife to the point that it has become a usual way of campus life. Cohabitation is generally seen as an act of a man and woman living together and sometimes having marital relationships without being married. Observation from a cursory look at our various campuses today showed that a large number of unmarried students indulge in the act of co-habiting which has resulted into poor academic performance and dreaded diseases while in school.

Cohabiting students most likely come in contact with deadly transmitted infections and the much dreaded HIV/AIDS disease. This practice of cohabiting has serious health issue to the female students that may indulge in the use of oral contraceptive unwanted pregnancy that may lead to truncated educational aspirations. But when pregnancy does occur, sometimes, the female student is more like to seek abortion as a way out. This practice of seeking for abortion may lead to another problem of exposing the female students to quack doctors who are not licensed practitioners and this may result in a whole of health complications with serious negative spillover effects in the long run (Ofoegbu, 2002). However, some students may frown at abortion giving birth to unwanted babies that were not planned for and all the consequences that come with it including a threatened academic pursuit.

This is evident in the yearly result obtained by students of tertiary institutions in north central Nigeria. The dwindling performance has also resulted into half backed graduates who cannot with stand the test of time in the business world. Government policy on students' hostel accommodation may have its good side but from the researcher's observation, the inability of the institutions in expanding and building new hostels has forced several students to look outward for accommodation. This has led to the emergence of an unacceptable trend in most tertiary institutions. Some call it campus marriage which is conventionally known as "cohabitation" among students, since it's an indecent act perpetrated on and off campus. The problem of this study therefore is: what is the investigation of co-habitation on academic achievement among students of Tertiary Institution in Niger state of Nigeria?

\section{RESEARCH QUESTIONS}

The following research questions are raised to direct the study:

1. What is the level of cohabitation among students of tertiary institutions?

2. How do social factors as an aspect of cohabitation influence students' academic achievement?

\section{Statement of hypotheses}

The following null hypotheses are formulated to direct the study

1. The level of cohabitation among students of tertiary institutions is not significantly high

2. There is no significant influence of social factor as an aspect of cohabitation on students' academic achievement.

\section{RESEARCH METHODOLOGY}

The research design to be adopted for this study is the survey design. Survey research is a method which involves a structured questionnaire given to respondents for eliciting information regarding their behaviour, intentions, attitudes, awareness and motivations pertaining to the phenomena at hand. The descriptive survey design was relevant to this study as the researcher was only to report the socioeconomic factors that influence the student's academic performance without manipulating variables.The population for this research study consists all the tertiary institutions in Niger state of Nigeria numbering seven thousand seven hundred and one $(7,701)$ students from three tertiary institutions.Stratified and simple random sampling techniques were used to select the required respondents in the study. The first stage involves the stratification of the population into states. The second stage was stratification based on the number of institutions that were considered in the study, $20 \%$ of students were randomly selected to constitute the sample of institution to participate in the study.A sample of seven hundred and ten (710) final year students' of three tertiary institutions, consisting of one federal university, one polytechnic and one federal college of education respectively all in Niger state.

The instrument for data collection was a researchers' developed instrument entitled Investigation of Co-habitation and Academic Achievement Score (PCAAAS). The instrument will comprise three sections; section A elicited information on personal data of the respondents. Section B will be a 20 items on the various aspect of perceived indicators of co-habitation namely social, economical, education and religious factors, while section $\mathrm{C}$ was a structured academic performance test in use of English which was administered to the students. To ascertain the face and content validity of the instrument was given to three 
experts two in Measurement and Evaluation and one in Guidance and Counselling for appropriate modifications. Their various suggestions and modifications by the experts were incorporated in the final copy of the instruments before administration. The reliability of the instrumentswas established using split half reliability co-efficient method. Some copies of the instruments will be administered to 40 students in the population that were not part of the final study. After the administration, the instrument was split into two equal halves and the reliability was determined with Pearson's Product Moment correlation statistics and later converted to Spearman Rank Order Correlation in order to step up the reliability index and the index ranged from .71 to .82

Data were collected through the administration of the instrument using eight research assistants. In each school, the researchers' assures the students of confidentiality in terms of responses supplied. The researchers also encourage the respondents to rate themselves as honest as possible in completing the questionnaire. All copies of the questionnaire administered were retrieved at the spot to ensure 100 percent return from the sampled schools. Uniform system of administering the copies of questionnaire will be adopted in all the schools and copies given out will be retrieved on the same day of administration. The hypotheses of this study were restated in the null form, descriptive and inferential statistic was used in the data analysis which is presented below:

\section{RESULTS AND DISCUSSION}

The results of the data collected are presented hypothesis-by-hypothesis as shown below.

The level of cohabitation among students is not significantly high

Hypothesis one:The only variable involve in this hypothesis is the level of cohabitation which was analyse with population t-test analysis and the result is presented in Table 1.

Table 1: results of the level of cohabitation among students

\begin{tabular}{llllll}
\hline Variable & $\mathrm{N}$ & $\mathrm{X}$ & $\mu$ & $\mathrm{SD}$ & $\mathrm{p}$-value \\
\hline $\begin{array}{l}\text { Level of } \\
\text { cohabitation }\end{array}$ & 707 & 16.02 & 10.11 & 2.06 & .001 \\
\hline$* \mathrm{p}<.05$ & & & & &
\end{tabular}

It is glaring that from Table 1 that the hypothesis of the level of cohabitation among students is not significantly high was rejected as the p-value of .001 was found to be less than the chosen alpha of .05was rejected. This implies that the level of cohabitation among students is significantly high.

Hypothesis two: There is no significant influence of social factor as an aspect of cohabitation on students' academic achievement in English Language. The independent variable of this hypothesis is social factor with three levels namely; highly social, moderately social and lowly social. The dependent variable is academic achievement in English Language. To test this hypothesis, One-Way ANOVA was employed, is presented in Table 2. 
International Journal of Advances in Scientific Research and Engineering (ijasre), Vol 5 (10), October-2019

TABLE 2.Summary of One-way Analysis of Variance with the influenceof social factor

on academic achievement in English Language

\begin{tabular}{|c|c|c|c|c|c|}
\hline Social factor & & & $\mathrm{N}$ & $\mathrm{X}$ & SD \\
\hline High & & & 265 & 16.17 & 3.43 \\
\hline Moderate & & & 226 & 15.45 & 3.61 \\
\hline Low & & & 216 & 14.13 & 3.51 \\
\hline Total & & & 707 & 15.69 & 3.52 \\
\hline Sources of variance & Sum of squares & df & Mean square & p-value. & \\
\hline Between Group & 86.29 & 2 & 43.145 & & \\
\hline & & & & .001 & \\
\hline With Groups & 8113.492 & 705 & 11.51 & & \\
\hline Total & 8199.785 & 707 & & & \\
\hline
\end{tabular}

TABLE 3.Post-hoc comparison with Fisher's Least Significance Different (LSD) on levels of social factor

\begin{tabular}{lllll}
\hline Levels of social factor & $\mathrm{N}$ & High & Moderate & Low
\end{tabular}

\begin{tabular}{lcccc}
\hline High & 265 & 16.17 & $.73^{*}$ & $2.05^{*}$ \\
Moderate & 226 & 2.32 & 15.45 & $1.32^{*}$ \\
Low & 216 & 5.51 & 3.57 & 14.13
\end{tabular}

$\mathrm{MSW}=11.51$

$*<.05$, critical $\mathrm{t}=1.960, \mathrm{df}=705$.

$\mathrm{a}=$ Group means are placed along the diagonal

$\mathrm{b}=$ Difference between group means are placed above diagonal

$\mathrm{c}=$ Fisher LSD are placed below the diagonal

Results in Table 2 shows that there were 707 respondents in the sample that constituted the analysis of the study namely high (265), moderate (226), and low (216). The means values for the three groups are 16.17, 15.45 and 14.13 with standard deviation of 3.43, 3.61 and 3.51 respectively. Results of the inferential statistics revealed that the p-value was found to be .001, which is less than the chosen alpha of 0.05 thus, the null hypothesis is rejected which implies that there is a significant influence of social factor as an aspect of cohabitation on students' academic achievement in English Language. Since the null hypothesis was rejected, a Post-hoc multiple comparisons was calculated with Fisher's Least Significant Difference (LSD) and presented in Table 3.

The means comparison with Fisher's Least Significant Difference (LSD) in Table 3, revealed that the mean differences for high and moderate level of social factor on cohabiting students has a statistical mean difference as $(\mathrm{t}=-2.32 ; \mathrm{p}=.010, \mathrm{X}=.73)$. For moderate and low levels of social factor on cohabiting students, the mean difference is statistically significance as ( $\mathrm{t}=5.51$; $\mathrm{p}=.000, \mathrm{X}=2.05$ ), while for moderate and low level of social factor on cohabiting students also a statistical mean difference as 
$(\mathrm{t}=-3.57 ; \mathrm{p}=.002, \mathrm{X}=1.32)$. The mean difference for high and low, high and low and moderate and low has a significant means differences.

\section{SUMMARY ON FINDING}

The findings indicate that there is high level of cohabitation among students in the study area. Thus, Omonijo (2015) attribute the prevalence (high level) of cohabitation among Nigeria youths to sex revolution in Europe and America. The author emphasised that the impact of foreign ideas, values and norms as well as social and mass communication and conditions of urban life on the behaviour and attitude of Nigerian adolescents are on the increase. On how social factor influence cohabitation and students academic achievement, the finding shows a significant influence on cohabitation on academic performance of students as Zheng (2011) The findings illustrate that social factors is a strong determinant of cohabitation among students in tertiary institutions..

Examining the extent to which social factors as an aspect influence academic performance of cohabiting students, majority of the students indicated that most of them cohabit to gain social influence and protection from their spouse. Thus, Nyirongo (2009) findings revealed that social factor has a significant impact on students' cohabitation. To this end, most student cohabitation as most of them feels that they cohabit because of the social influence of their spouse in school. It was also found that most students who cohabit feel that their intentions of cohabiting are directly dependent on the need to be influential in school.

\subsection{Summary Of The Study}

The purpose of the study was to carry out an investigation of co-habitation and academic achievement among students of tertiary institutions in Niger state.Two research questions and hypotheses were formulated to guide the study and the study employee descriptive survey research design. Questionnaires were used to solicit information from the students. The target population of the study consisted of 7001 respondents drawn from three tertiary institutions of higher learning. The samples were selected using stratified and simple random sampling; Data from the questionnaires were analyzed using SPSS package, while data interpretation was done using, population t-test, independent t-test and one way ANOVA.

\section{CONCLUSION}

Cohabitation among students of tertiary institutions in Niger state of Nigeria quite common and caused mainly by lack of accommodation, problems with roommates, educational, social and economic factors among others. The students perceive cohabitation as normal and none of the business of their friends in school. The high awareness of cohabitation among the students generally suggests the acceptance of this living style. However the students were not counseled to handle the sociocohabitation. Most of the cohabiting students refused to let their parents know about their cohabitation status while inschool. Therefore the idea of cohabiting with someone your parents never approved portends a great danger to thestudents when things go wrong. Moreover, the school security may not be able to regulate the conducts of studentsliving off campus where cohabitation. The root cause of cohabitation among students in tertiary institutions been observed that the university has more male hostels than female hostels in the campus. This makes it difficult for the school to adequately carter for the accommodation needs of numerous female students in the university. This lack of accommodation for female students predisposes them to search for alternative means of accommodation with the options of cohabitation often available. Cohabitation could influence the life and attitude of the students positively or negatively. It exposes students to pre marital sex, unwanted pregnancies, abortion complications and sexually transmitted diseases. The trauma the students encounter at this stage could affect future relationships and perception of opposite sex.

On the other hand, where the cohabiters have good experiences it fosters tolerance, and encourages them to know each other better for a permanent future relationship through marriage. Another important issue here is the age at which the students engage in cohabitation. It was observed that some of the students were in their late teens early 20 s and were not ready for marriage. They just see cohabitation as fun and opportunity to explore their new found independence and liberty in school.

\section{RECOMMENDATIONS}

Based on the findings the following recommendations were made:

1. Parents should have interest in their children's education. This is because students would perform better academically with parent's involvement. Parents should also be encouraged to buy extra textbooks and other learning material for the students to use at home especially for day scholars.

2. Government should provide textbooks and other learning materials required by secondary school learners in all secondary schools. 


\section{REFERENCES}

1. Bower, D. W. \&Christopherson, V. A. (2001). University Student Cohabitation: A Regional Comparison of Selected Attitudes and Behaviour', Journal of Marriage and Family, 39(3), 447-453

2. Bumpass, L. L. \& Lu, H. (2000) 'Trends in cohabitation and implications for children's family contexts in the United State', Population Studies, 54: 29-41

3. Clarberg, M. (1999). The Price of Partnering: The Role of Economic Well-being in Young Adults'First Union Experiences. Social Forces 77, 3: 945-969.

4. Clarkberg, M, Ross, M. Stolzenberg\& Linda J. W. (2015). Versus Marital Unions. Social ForcesKramer, Elise (2004). "Cohabitation: Just a Phase?"

5. Ermisch, J. \&Francesconi, M. (2000). Cohabitation in Great Britain: Not for long, but here to stay. Journal of the Royal Statistical Society, 163 (2),153-171.

6. Kiernan, K. (2001) 'The Rise of Cohabitation and Childbearing Outside Marriage in Western Europe', International Journal of Law, Policy and the Family, 15: 1-21 Vol.20 No.2 2017

7. Kramer B. (2004). Spatial Analysis of Cohabiting Tertiary Students' Housing Location in Ibadan, Nigeria. Geo-Journal, 81(6): DOI: $10.1007 / \mathrm{s} 10708-016-9758-3$

8. Mashau, T. D. (2011). Cohabitation and premarital sex amongst Christian youth in South Africa today: A Theological Studies, 67(2), 1-7.

9. Nyagosia, P.O. (2011). Determinants of Differential Kenya Certificate of Secondary Education Performance and School Effectiveness in Kiambu and Nyeri Counties, Kenya. Kenyatta University. Retrieved April 25, 2018 from http://irlibrary.ku.ac.ke/bitstream/handle/123456789/3009/Nyagosia,\%20Patrick\%20Ogecha. pdf?sequence=3

10. Ofoegbu, C. I., (2002). Human Development, Family Enugu: Snaap Press Ltd.

11. Ogunsola, M.O. (2004). Premarital behaviour and length of courtship as determinant of marital stability among couples in Oyo State, Nigeria. Unpublished M.Ed project University of Ibadan, Ibadan.

12. Omonijo R. (2015). The effect of premarital cohabitation on quality of relationship and marital stability of married people in Southwest, Nigeria. African Nebula, Issue 3, 16-24.

13. Perelli-Harris, B. \&Gassen, N. S. (2012). How Similar Are Cohabitation and Marriage. Legal Approaches to Cohabitation across Western Europe', Population and Development Review, 7 (38), 435-467.

14. Rabušic, L.O. (2001). On Current Developments in Marriage and Family Behaviour in the Czech Republic). Demographic38, 3: 173-180.

15. Rindfuss, R.R. \&Venden-Heuvel, A. (2000). Cohabitation: A Precursor to Marriage or an Alternative to being Single. Population and Development Review, 16: 703-726.

16. Svodziwa, M. \&Kurete, F. (2017). Cohabitation among Tertiary Education Students: An Exploratory Study in Bulawayo. Journal of Human and Social Studies, 6 (1), 138-148.

17. Vereš, P. (2011). "Několikúvah o současném a budoucímpopulačnímvývoji“ Some Thoughts onthe Present and Future Population Development, 33, 2: 97-104.Sociologickýčasopis/Czech Sociological Review, 38, (6), 23-26

18. Zheng, L. (2011). Cohabitation and Marital Stability: Quality or Commitment?"Journal of Marriage and the Family 54, 2: 259-268. 